\title{
SARCOPENIA AND SARCOPENIC OBESITY IN OLDER COMMUNITY-DWELLING ADULTS WITH FAVORABLE HEALTH CONDITIONS
}

\author{
E. Ramirez-García ${ }^{1}$ K. Moreno-Tamayo ${ }^{1}$, S.C. Briseño-Fabiann ${ }^{2}$ S. Sánchez-García ${ }^{1}$
}

\begin{abstract}
Objective: Determine the prevalence of sarcopenia and sarcopenic obesity in community-dwelling older adults with favorable health conditions using the diagnostic criteria from the European Working Group on Sarcopenia in Older People (EWGSOP). Design: Cross-sectional study. Setting/Participants: Including 197 older adults representing a population-based sample $(\mathrm{n}=1,252)$ from baseline (year 2014) of the Cohort of Obesity, Sarcopenia and Frailty of Older Mexican Adults (COSFOMA). Measurements: Anthropometric and body composition measurements were performed using bioelectric impedance analysis (BIA). Walking speed was determined with walking time of $4.5 \mathrm{~m}(<0.8 \mathrm{~m} / \mathrm{s})$, grip strength with dynamometer (women $<20 \mathrm{~kg}$ and men $<30 \mathrm{~kg}$ ) and muscle mass using BIA (muscle mass index: women $<6.1 \mathrm{~kg} / \mathrm{m}^{2}$ and men $<8.5 \mathrm{~kg} / \mathrm{m}^{2}$ ). The cutoff point for low muscle mass was set at $2 \mathrm{SD}$ below average for a group of young adults. For obesity, body fat percentage $>60$ th percentile was considered (38.4\% female and $26.7 \%$ male). A p value $<0.050$ was considered statistically significant. Results: Mean age of the 197 older adults (44.2\% female and 55.8\% male) was 66.4 years (5.6): women 66.6 years (5.6) and men 66.4 years (5.8). The prevalence of sarcopenia was $7.1 \%$ (women $6.9 \%$ and men $7.2 \%$ ). The presence of sarcopenic obesity was $2.5 \%$ (women $1.1 \%$ and men $3.6 \%$ ). Conclusion: The magnitude of sarcopenia in older adults is important despite the absence of adverse health effects. This finding provides a reference point for future studies.
\end{abstract}

Key words: Sarcopenia, sarcopenic obesity, low muscle mass, favorable health conditions.

\section{Introduction}

The aging process is linked to a physiological decrease in organ function (1). The progressive and involuntary loss of muscle mass and strength known as sarcopenia (2) has become relevant because the condition increases the probability of presenting adverse health outcomes such as falls, physical disability, loss of autonomy, lower quality of life and increased mortality $(3,4)$. This phenomenon can develop in parallel to obesity, leading to musculoskeletal catabolism and decreased physical performance, which may lead to the development of sarcopenic obesity (SO) (5).

The prevalence of sarcopenia in older adults has presented important variations with values ranging from

1. Unidad de Investigación en Epidemiología y Servicios de Salud, Área Envejecimiento, Centro Médico Nacional Siglo XXI, Instituto Mexicano del Seguro Social (IMSS), Ciudad de México, México; 2. Unidad de Medicina Familiar No.14, Instituto Mexicano del Seguro Social (IMSS), Col. Moctezuma D.F, México.

Corresponding Author: S. Sánchez-García, Unidad de Investigación en Epidemiología y Servicios de Salud, Avenida Cuauhtémoc No. 330, Edificio CORCE. Tercer piso. Col. Doctores, Delegación Cuauhtémoc, Ciudad de México. Código Postal 06725. México, sergio.sanchezga@imss.gob.mx; ssanchezga71@gmail.com.
$0.1 \%-85.4 \%$ attributed to the diagnostic method, cut-off points used, study population and even geographical area, among others (6). Likewise, SO may present variations depending on the frequency with which obesity occurs in the study population $(5,7)$. In 2010 the European Working Group on Sarcopenia in Older People (EWGSOP) agreed on a practical and diagnostic definition for clinical and research purposes in order to unify measurement methods and to obtain accurate estimates of this disease (2).

A recent systematic review on the prevalence of sarcopenia (8) suggests that ethnicity plays an important role in referring to diagnostic criteria; therefore, it has been recommended to clearly define the profile of the study population.

Because sarcopenia represents multifactorial causality (9), its prevalence can be modified by the epidemiological profile of the study population because of its relationship with other comorbidities. Sarcopenia can occur more frequently in older adults with health challenges than those with favorable health conditions (10). In this sense, it is interesting to study sarcopenia in a population sample of older adults with favorable health conditions because it can serve as a point of comparison for the 
study of sarcopenia regardless of other unfavorable health conditions. The objective of this study is to determine the prevalence of sarcopenia and $\mathrm{SO}$ in older adults with favorable health conditions living in Mexico City using the diagnostic criteria of the EWGSOP.

\section{Methods}

\section{Participants}

An observational, cross-sectional, populationbased study was carried out in adults $\geq 60$ years of age. Subjects were beneficiaries of the Mexican Institute of Social Security (IMSS) and lived in Mexico City. Data represent the baseline (year 2014) of the Cohort of Obesity, Sarcopenia and Frailty of Older Mexican Adults (COSFOMA), which included 1,252 participants with heterogeneous health conditions. Participants were chosen through a simple random selection from a master frame of the 48 Family Medicine Units (FMU) of the IMSS in Mexico City (11).

Sample size for determination of the prevalence of sarcopenia was calculated assuming that $33 \%$ of the older adults presented sarcopenia (12), with an accuracy of $\pm 2 \%$ and a $95 \%$ confidence interval. The minimum sample size was 857 older adults.

A subsample of older adults with favorable health conditions was selected for the study according to the following inclusion criteria: functional capacity, wellconserved cognitive and nutritional status (evaluated from the Barthel Index $>90$ points, Mini-Folstein Mental State Examination $\geq 25$ or $\geq 19$ in illiterate subjects, MiniNutritional Assessment $\geq 24$, respectively) and good selfperceived health. Exclusion criteria were those subjects with comorbidities included in the Elixhauser index, polypharmacy ( $\geq 3$ medications), hospital admissions in the last year, depressive symptoms and anxiety ( $\geq 16$ points in the revised version of the Center for Epidemiologic Studies Depression CESD-R; $\geq 23$ points on the Short Anxiety Screening Test in Seniors, SAST, respectively). Also excluded were those subjects who presented a history of fracture(s) in the upper or lower limbs, use of pacemakers, or those who intentionally presented weight loss $(\geq 3 \mathrm{~kg}$ in the last year, in addition to having detection and control of overweight or obesity by health personnel). Participants without electrical bioimpedance (BIA) data were eliminated.

The subsample consisted of 197 older subjects with favorable health conditions who had standardized anthropometric measurements (weight and height) and body composition as well as sociodemographic information (age and gender).

\section{Evaluation of sarcopenia and SO}

Sarcopenia was evaluated based on the criteria proposed by the EWGSOP, measuring muscle mass (MM) using BIA with RJL Systems BIA 101, walking speed (WS) by $4.5 \mathrm{~m}$ walking time (usual pace) and grip strength (GS) with Takei TKK 5001 dynamometer (Takei Scientific Instruments Co. Ltd., Tokyo, Japan).

The presence of low MM defined as muscle mass index (MMI) was $<6.1 \mathrm{~kg} / \mathrm{m}^{2}$ in women and $<8.5 \mathrm{~kg} / \mathrm{m}^{2}$ in men. The cutoff point for low MM was set at 2 SD below the gender-specific mean of a group of young Mexican adults (Table 1); low WS $<0.8 \mathrm{~m} / \mathrm{s}$; low GS $<20 \mathrm{~kg}$ women and $<30 \mathrm{~kg}$ in men. In addition, the severity of sarcopenia was classified as severe if it fulfilled three criteria, moderated by at least two criteria (low MM, lower WS or GS) and presarcopenia with only low MM. SO was defined based on the EWGSOP criteria plus high body fat percentage (BFP) ( $>60$ th percentile by gender and assessed by BIA). Figure 1 shows the evaluation process for the mentioned criteria.

Table 1

Characteristics of the sample of young Mexican adults (18-40 years)

\begin{tabular}{llll}
\hline Characteristics & $\begin{array}{l}\text { Female } \\
\text { (n=138) } \\
\text { Mean (SD) }\end{array}$ & $\begin{array}{l}\text { Male } \\
\text { (n=92) } \\
\text { Mean (SD) }\end{array}$ & p-value $^{\dagger}$ \\
\hline Age (years) & $26.8(6.9)$ & $28.0(7.2)$ & 0.190 \\
Height (m) & $157.2(5.8)$ & $170.1(6.9)$ & $<0.001$ \\
Weight $(\mathrm{kg})$ & $62.4(15.1)$ & $76.9(14.3)$ & $<0.001$ \\
Muscle mass $(\mathrm{kg})$ & $19.4(2.5)$ & $31.0(3.7)$ & $<0.001$ \\
MMI $\left(\mathrm{kg} / \mathrm{m}^{2}\right)$ & $7.9(0.9)$ & $10.7(1.1)$ & $<0.001$ \\
\hline
\end{tabular}

$\mathrm{SD}$, standard deviation; MMI, muscle mass index. ${ }^{+}$Statistical value (Student $\mathrm{t}$ test for independent samples).

Figure 1

Diagnostic algorithm of sarcopenia and sarcopenic obesity (SO)

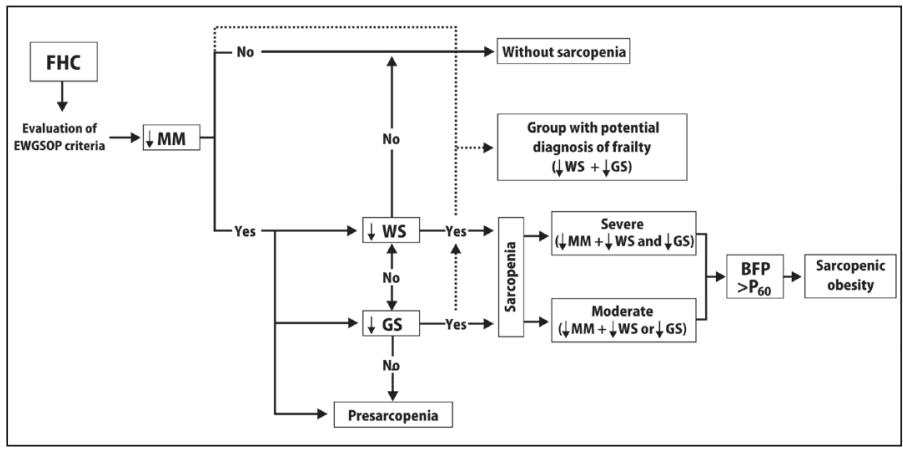

FHC, older adults with favorable health conditions; $\downarrow$ MM, low muscle mas index; $\downarrow W S$, low walking speed; $\downarrow$ GS, low grip strength; BFP $>$ P60, body fat percentage $>60$ th percentile.

BIA was performed with a standard technique using a single frequency of $50 \mathrm{kHz}$. Four electrodes were placed 
Table 2

Anthropometric characteristics and physical performance of community-dwelling older adults with favorable health conditions in Mexico City

\begin{tabular}{|c|c|c|c|c|}
\hline & $\begin{array}{l}\text { Total } \\
(\mathrm{n}=197) \\
\text { Mean (SD) }\end{array}$ & $\begin{array}{l}\text { Female } \\
(\mathrm{n}=87) \\
\text { Mean (SD) }\end{array}$ & $\begin{array}{l}\text { Male } \\
(\mathrm{n}=110) \\
\text { Mean (SD) }\end{array}$ & p-value ${ }^{\dagger}$ \\
\hline Height $(\mathrm{cm})$ & $158.5(9.2)$ & $151.5(6.0)$ & $164.0(7.3)$ & $<0.001$ \\
\hline Weight (kg) & $69.6(13.4)$ & $64.9(12.1)$ & $73.4(13.2)$ & $<0.001$ \\
\hline MM (kg) & $22.0(5.9)$ & $16.6(3.0)$ & $26.2(3.8)$ & $<0.001$ \\
\hline MMI $\left(\mathrm{kg} / \mathrm{m}^{2}\right)$ & $8.6(1.7)$ & $7.2(1.1)$ & $9.7(1.1)$ & $<0.001$ \\
\hline WS $(\mathrm{m} / \mathrm{s})$ & $1.1(0.3)$ & $1.2(0.3)$ & $1.1(0.3)$ & 0.017 \\
\hline GS (kg) & $26.0(8.9)$ & $19.2(5.3)$ & 31.5 (7.3) & $<0.001$ \\
\hline $\mathrm{BFP}(\%)$ & $30.0(8.1)$ & $35.6(7.4)$ & $25.6(5.5)$ & $<0.001$ \\
\hline
\end{tabular}

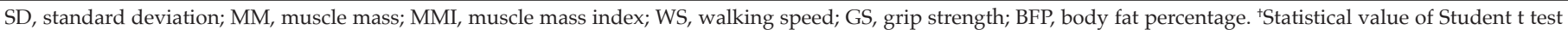
(for independent variables).

in a distal position (two electrodes at the hand level and two electrodes at the ipsilateral foot) in supine position and with the lower limbs in abduction at $45^{\circ}$ and the upper limbs at $30^{\circ}$ abduction. After analysis, the values of resistance and reactance were recorded. MM was calculated using the formula of Jansenn et al. (11).

\section{Statistical analysis}

Frequencies were calculated for qualitative variables and mean and SD for quantitative variables. For comparison of proportions, $\mathrm{X}^{2}$ test or Fisher test was performed and mean comparison using the Student $t$ test for independent samples. Pearson correlation was calculated to determine the relationship between the quantitative variables of the diagnostic criteria of sarcopenia and SO (MMI, WS, GS and BFP); p value $<0.050$ was considered statistically significant. Data were analyzed using the IBM-SPSS 23 program (SPSS Inc., Chicago, IL) for Windows.

\section{Results}

The group of older adults with favorable health conditions was comprised of 197 subjects of whom $44.2 \%$ were women and $55.8 \%$ were men. Mean age was 66.4 (5.6) years; women 66.6 (5.6) and men 66.4 (5.8). There was no significant difference in age between men and women $(\mathrm{p}=0.835)$. Regarding the sarcopenia criteria, $13.2 \%$ presented low MM, 10.3\% female and $15.5 \%$ male, $\mathrm{p}=0.293$; low WS $12.2 \%, 11.8 \%$ women, $12.5 \%$ men, $\mathrm{p}=0.896$, and low GS $51.8 \%, 56.3 \%$ women, $48.1 \%$ men, $\mathrm{p}=0.256$. The mean of the BFP estimate for the entire sample was 30.0 (8.1), 35.6 women and 25.6 men, $\mathrm{p}<0.001$. The 60th percentile for BFP was $31.7 \%$, $38.4 \%$ female and $26.7 \%$ male. In Table 2, the main anthropometric characteristics and physical performance of the study sample are presented. The correlation among the three criteria and the BFP was low to moderate. In all cases it was statistically significant $(p<0.050)$.

The different combinations of the diagnostic criteria for sarcopenia as well as their respective prevalences are shown in Table 3. The overall prevalence of sarcopenia was $7.1 \%$, women $6.9 \%$ and men $7.3 \%$; however, no statistically significant differences were found $(p=0.919)$. The combination of criteria with a higher prevalence was low MM + GS (4.6\%) followed by low MM + GS + WS $(1.5 \%)$ and, finally, low MM + WS (1\%). The low GS + WS group had a frequency of $12.2 \%$. When comparing the different combinations between men and women of the EWGSOP criteria in low MM + GS + WS $(\mathrm{p}=0.256)$; low MM + WS $(\mathrm{p}=1.000)$; low MM + GS $(\mathrm{p}=0.481)$, no statistically significant differences were observed.

The group most affected by sarcopenia was that with the oldest age ( $\geq 80$ years) with a prevalence greater than double $(16.7 \%)$ compared to the group of $60-69$ years $(6.9 \%)$, which was very similar to the intermediate group of 70-79 years $(6.5 \%)$; however, no statistically significant differences were found between these groups ( $p>0.050)$.

Frequency and distribution of the severity of sarcopenia by gender and age groups is shown in Table 4. The severity group where the highest prevalence was found was moderate sarcopenia (5.6\%). It should be noted that the presarcopenia group also had an important prevalence $(6.1 \%)$. When analyzing severity by gender, a pattern was observed in women as follows: severe $0 \%$, moderate $6.9 \%$, presarcopenia $3.4 \%$. However, in men the frequency of severe sarcopenia was $2.7 \%$, moderate $4.5 \%$, and $8.2 \%$ presarcopenia, respectively. Comparison by gender was not statistically significant ( $p>0.050) ; 2.5 \%$ of the entire sample met the criteria of sarcopenic obesity, $1.1 \%$ in women and $3.6 \%$ in men without significant differences $(\mathrm{p}=0.270)$. 


\section{Discussion}

In older adults with favorable health conditions, $7 / 100$ have sarcopenia without a gender predominance, suggesting that sarcopenia similarly affects women and men with favorable health conditions.

In this study the findings were within the range $(1 \%-29 \%)$ reported in the literature in older people who were evaluated for sarcopenia from the criteria proposed by the EWGSOP (8). It should be noted that the prevalence of sarcopenia in studied populations may be affected by the health conditions of older adults. To our knowledge, only one study in Latin America adheres to the EWGSOP criteria and, in particular, to the recommendations for the measurement of muscle mass. This study was performed in a population $\geq 60$ years of age living in the Brazilian urban community (14). A general prevalence was reported of $15.4 \%$ (16.1\% in women and $14.4 \%$ in men). In this study, the prevalence by gender did not show statistically significant differences as in the present study. It should be mentioned that, in the Brazilian study, multiple adverse health effects were included in the analyzed sample, which could be attributed to a higher prevalence.

\section{Table 3}

Frequency and distribution of criteria patterns for diagnosis of sarcopenia proposed by the EWGSOP in a sample of community-dwelling older adults with favorable health conditions in Mexico City

\begin{tabular}{lllll}
\hline $\begin{array}{l}\text { Criteria } \\
\text { Low MM/Low WS/ } \\
\text { Low GS }\end{array}$ & $\begin{array}{l}\text { Total } \\
\%(\mathbf{n})\end{array}$ & $\begin{array}{l}\text { Female } \\
\%(\mathbf{n})\end{array}$ & $\begin{array}{l}\text { Male } \\
\%(\mathbf{n})\end{array}$ & p-value \\
\hline YYY $^{\mathrm{a}}$ & $1.5(3)$ & $0(0)$ & $2.7(3)$ & $0.256^{+}$ \\
$\mathrm{YYN}^{\mathrm{b}}$ & $1.0(2)$ & $1.1(1)$ & $0.9(1)$ & $1.000^{+}$ \\
$\mathrm{YNY}^{\mathrm{b}}$ & $4.6(9)$ & $5.7(5)$ & $3.6(4)$ & $0.481^{*}$ \\
$\mathrm{YNN}^{\mathrm{c}}$ & $6.1(12)$ & $3.4(3)$ & $8.2(9)$ & $0.168^{*}$ \\
$\mathrm{NYY}$ & $12.2(24)$ & $16.1(14)$ & $9.1(10)$ & $0.136^{*}$ \\
$\mathrm{NYN}$ & $8.1(16)$ & $5.7(5)$ & $10.0(11)$ & $0.278^{*}$ \\
$\mathrm{NNY}$ & $33.0(65)$ & $34.5(30)$ & $31.8(35)$ & $0.693^{*}$ \\
$\mathrm{NNN}$ & $33.5(66)$ & $33.3(29)$ & $33.6(37)$ & $0.964^{*}$ \\
Sarcopenia & $7.1(14)$ & $6.9(6)$ & $7.3(8)$ & $0.919^{*}$ \\
SO & $2.5(5)$ & $1.1(1)$ & $3.6(4)$ & $0.270^{*}$ \\
\hline
\end{tabular}

${ }^{\dagger}$ Fisher exact test; * $\mathrm{X}^{2}$; MM, muscle mass; WS, walking speed; GS, grip strength; $\mathrm{SO}$, sarcopenic obesity; $\mathrm{Y}$, criteria present; $\mathrm{N}$, criteria absent, respectively; a. Severe sarcopenia; b. Moderate sarcopenia; c. Presarcopenia.

A study carried out in Spain (12) with an adult community-dwelling population 70-80 years of age characterized as "healthy" evaluated the prevalence of sarcopenia based on the criteria proposed by the EWGSOP. This study reported sarcopenia prevalence of $33 \%$ for women and 10\% for men. Comparing this with the findings of the present study, the prevalence in men is similar; however, that of women is only slightly more than threefold. It should be pointed out that, in both studies, control of adverse health effects was considered to characterize a sample of older adults in the best health conditions; however, they differ in the prevalences found in females. This may be due to the fact that the Spanish population included adults older than those in the present study and, in addition, simple selection was based on less rigorous criteria that could allow inclusion of some health deficits. It is also thought that this difference may be related to the biological characteristics in which the expression of various biological markers associated with the pathophysiology of sarcopenia is implicated (15-18) and will depend on the genetic components present in the individuals of each study population. Together these present a series of interactions with characteristics of the external environment such as the geographic or regional area, culture, habits and lifestyles that can facilitate the series of events that trigger the pathological process of sarcopenia.

The proportion of presarcopenia is striking because this resembles that of general sarcopenia. This group is of special interest for its follow-up because it meets the criterion of low MM and is the most susceptible to change to a diagnosis of sarcopenia. In the future this could represent the increase in the number of cases with the deleterious effects that it entails. When observing the prevalence of presarcopenia by gender, no difference was found between women and men. There are probably data indicating that gender plays an important role, at least in this group of presarcopenic individuals. Therefore, gender-specific biological characteristics may be present during the development of sarcopenia.

For SO, a prevalence of $2.5 \%$ was found in the general population, being more than threefold as high in men as in women (3.6\% and $1.1 \%$, respectively). Worldwide prevalence of SO ranges from 3.6-94.0\% (1921). Currently, several methodologies are used for its measurement without agreement (19). This has allowed wide variations in its measurement, considering the different characteristics of the study population.

In the present study the prevalence of $\mathrm{SO}$ was low and no difference was found according to gender. This idea reinforces the principle that if the sample was expanded it would possibly show significant statistical differences and may point to a greater affection in males in the analyzed population. The group with severe sarcopenia had a similar behavior where males were the most affected. According to these findings, the most complex forms of sarcopenia occur in males. In addition to this, the prevalence found is low compared to that reported in other studies and may be due to the fact that the analyzed study sample had favorable health conditions. This fact conditioned the selection of those with the least exposure to factors that could influence the appearance of this disease.

Another group of interest was the group who presented low GS + WS because it had a prevalence of $12.2 \%$. This group presents two of the criteria for the 
Table 4

Frequency and distribution according to sex and age group of the severity of sarcopenia in community-dwelling older adults with favorable health conditions according to the EWGSOP

\begin{tabular}{|c|c|c|c|c|c|}
\hline & $\begin{array}{l}\text { Total } \\
\%(\mathrm{n})\end{array}$ & $\begin{array}{l}60-69 \text { years } \\
\% \text { (n) }\end{array}$ & $\begin{array}{l}70-79 \text { years } \\
\% \text { (n) }\end{array}$ & $\begin{array}{l}\geq 80 \text { years } \\
\%(n)\end{array}$ & p-value \\
\hline \multicolumn{6}{|l|}{ Females } \\
\hline Severe sarcopenia & $0.0(0)$ & $0.0(0)$ & $0.0(0)$ & $0.0(0)$ & --- \\
\hline Moderate sarcopenia & $6.9(6)$ & $6.7(4)$ & $7.7(2)$ & $0.0(0)$ & $1.000^{+}$ \\
\hline Presarcopenia & $3.4(3)$ & $1.7(1)$ & $7.7(2)$ & $0.0(0)$ & $0.243^{+}$ \\
\hline Without sarcopenia & $89.7(78)$ & $91.7(55)$ & $84.6(22)$ & $100(1)$ & $0.502^{+}$ \\
\hline \multicolumn{6}{|l|}{ Males } \\
\hline Severe sarcopenia & $2.7(3)$ & $3.5(3)$ & $0.0(0)$ & $0.0(0)$ & $1.000^{+}$ \\
\hline Moderate sarcopenia & $4.5(5)$ & $3.5(3)$ & $5.0(1)$ & $20.0(1)$ & $0.165^{+}$ \\
\hline Presarcopenia & $8.2(9)$ & $5.9(5)$ & $20.0(4)$ & $0.0(0)$ & $0.107^{+}$ \\
\hline Without sarcopenia & $84.5(93)$ & $87.1(74)$ & $75.0(15)$ & $80.0(4)$ & $0.322^{+}$ \\
\hline \multicolumn{6}{|l|}{ Total } \\
\hline Severe sarcopenia & $1.5(3)$ & $2.1(3)$ & $0.0(0)$ & $0.0(0)$ & $1.000^{+}$ \\
\hline Moderate sarcopenia & $5.6(11)$ & $4.8(7)$ & $6.5(3)$ & $16.7(1)$ & $0.316^{+}$ \\
\hline Presarcopenia & $6.1(12)$ & $4.1(6)$ & $13.0(6)$ & $0.0(0)$ & $0.073^{*}$ \\
\hline Without sarcopenia & $86.8(171)$ & $75.4(129)$ & $80.4(37)$ & $83.3(5)$ & $0.319^{*}$ \\
\hline
\end{tabular}

EWGSOP, European Working Group on Sarcopenia in Older People; 'Fisher exact test; * Chi-cuadrada.

diagnosis of sarcopenia without the condition of low MM. It is not classified as sarcopenia, but it is striking because these criteria are also considered for the diagnosis of frailty according to the Fried model (22). Therefore, a potential diagnosis of frailty for this group could be suspected. This group appears to represent the limit between the diagnoses of sarcopenia and frailty. Based on this, its identification would suggest a priority follow-up group for the diagnosis of frailty or sarcopenia because it demonstrates high potential for outcome for either pathological entity. However, these findings are only suggestive and would require longitudinal studies to explore these aspects.

It was considered important to control the sample for the exclusion of multimorbidity and acute disease processes because this allowed greater certainty of the measurement of sarcopenia and the avoidance of the approach of other diseases related to similar pathological processes as in the case of cachexia. Although the selection process of the sample based on the criteria allows sarcopenia to be analyzed under favorable health conditions, it was also a limitation because it conditioned the reduction in the number of participants in the age groups, mainly in those persons $>70$ years old. However, the extent of sarcopenia in this age group was observed despite its small size. There was no age trend in sarcopenia, which is consistent with that reported in other studies (12,23-26). However, in the future a more in-depth longitudinal analysis is considered necessary.
Because sarcopenia is an entity that may manifest as one of the outcomes of the interaction of other health states $(10,27)$, analysis of this condition isolated from a large number of factors influencing the occurrence of sarcopenia allows a point of comparison for other investigations. It is worth mentioning that one of the most recommended methods of muscle mass measurement in research (and suggested worldwide) was used because it is one of the most usual, objective and reliable methods and allows us to compare to what has been reported in other regions.

Estimates of sarcopenia and SO were performed from a sample representing $>50 \%$ of community-dwelling older adults residing in Mexico City and the metropolitan area (28). This population is of great importance because it is one of the geographic areas with the greatest number of elderly inhabitants (29).

\section{Conclusions}

The magnitude of sarcopenia in older adults is important despite the absence of adverse health effects. This finding provides a reference point for future studies.

Acknowledgments: We thank the authorities and staff of the South and North Delegations of the Mexican Institute of Social Security (IMSS) of Mexico City for support for this study.

Funding: This work was supported by the Sector Fund Health Research and Social Security SS/IMSS / ISSSTE/CONACYT (México) SALUD-2013-01-201112 and the Fund for the Promotion of Health Research, IMSS, FIS/IMSS/PROT/ 
PRIO/13/024. The funders had no role in the design, execution, analysis and interpretation of data, or writing of the study.

Author Contributions: The following authors contributed to the theme of the study (E.R.-G., S.S.-G), planning analysis (E.R.-G., S.S.-G, K.M.-T) and interpretation of the results (E.R.-G., S.S.-G, K.M.-T, S.C.B.-F.) as well as in the reading and criticism of the writing (E.R.-G., S.S.-G, K.M.-T, S.C.B.-F.). We express that we have read and approved the manuscript and we are in agreement with the final version and the order of the authors (E.R.-G., K.M.-T, S.C.B.-F., S.S.-G) study.

Conflicts of Interest: The authors declare no conflict of interest in relation to this

Ethical standards: The present study adheres to the ethical principles for research in humans according to the original Helsinki Protocol Declaration. The COSFOMA protocol was approved by the National Commission of Scientific Research and Ethics Commission for Health Research (Registration numbers COFEPRIS 13 CI 09015213 for the Research Committee and COMBIOETICA 09 CEI 00920160601 for the Research Ethics Committee) of the IMSS. Prior to data collection, written informed consent was requested from each participant.

\section{References}

1. Boss G, Seegmiller J. Age-related physiological changes and their clinical significance. West J Med 1981;135:434-440.

2. Cruz-Jentoft AJ, Baeyens JP, Bauer JM, Boirie Y, Cederholm T, Landi F, Martin FC, Michel J-P, Rolland Y, Schneider SM, Topinkova E, Vandewoude M, Zamboni M. Sarcopenia: European consensus on definition and diagnosis: Report of the European Working Group on Sarcopenia in Older People. Age Ageing 2010;39:412-423. doi:10.1093/ageing/afq034

3. Janssen I, Heymsfield SB, Ross R. Low relative skeletal muscle mass (sarcopenia) in older persons is associated with functional impairment and physical disability. J Am Geriatr Soc 2002;50:889-896.

4. Janssen I. Skeletal Muscle Cutpoints Associated with Elevated Physical Disability Risk in Older Men and Women. Am J Epidemiol 2004;159:413-421. doi:10.1093/aje/kwh058.

5. Vincent HK, Raiser SN, Vincent KR. The aging musculoskeletal system and obesity-related considerations with exercise. Ageing Res Rev 2012;11:361-373. doi:10.1016/j.arr.2012.03.002.

6. Pagotto V, Aparecida-Silveira E. Methods, Diagnostic Criteria, Cutoff Points, and Prevalence of Sarcopenia among Older People. Sci World J 2014:1-11. doi: $10.1155 / 2014 / 231312$

7. Bales CW, Ritchie CS. Sarcopenia, Weight Loss, and Nutritional Frailty in the Elderly. Annu Rev Nutr 2002;22:309-323. doi:10.1146/annurev. nutr.22.010402.102715.

8. Cruz-Jentoft AJ, Landi F, Schneider SM, Zuniga C, Arai H, Boirie Y, Chen L-K, Fielding RA, Martin FC, Michel J-P, Sieber C, Stout JR, Studenski SA Vellas B, Woo J, Zamboni M, Cederholm T. Prevalence of and interventions for sarcopenia in ageing adults: a systematic review. Report of the International Sarcopenia Initiative (EWGSOP and IWGS). Age Ageing 2014;43:748-759. doi:10.1093/ageing/afu115.

9. Fielding RA, Vellas B, Evans WJ, Bhasin S, Morley JE, Newman AB, Abellan van Kan G, Andrieu S, Bauer J, Breuille D, Cederholm T, Chandler J, De Meynard C, Donini L, Harris T, Kannt A, Keime Guibert F, Onder G, Papanicolaou D, Rolland Y, Rooks D, Sieber C, Souhami E, Verlaan S, Zamboni M. Sarcopenia: An Undiagnosed Condition in Older Adults. Current Consensus Definition: Prevalence, Etiology, and Consequences. International Working Group on Sarcopenia. J Am Med Dir Assoc 2011;12:249-256. doi:10.1016/j.jamda.2011.01.003.

10. Beaudart C, Rizzoli R, Bruyère O, Reginster J-Y, Biver E. Sarcopenia burden and challenges for public health. Arch Public Health 2014;72. doi:10.1186/2049-3258-72-45.

11. Doubova S, Sánchez-García S, Infante-Castañeda C, Pérez-Cuevas R. Factors associated with regular physical exercise and consumption of fruits and vegetables among Mexican older adults. BMC Public Health 2016;9:952. doi:10.1186/s12889-016-3628-2.
12. Masanes F, Culla A, Navarro-Gonzalez M, Navarro-Lopez M, Sacanella E, Torres B, Lopez-Soto A. Prevalence of sarcopenia in healthy communitydwelling elderly in an urban area of Barcelona (Spain). J Nutr Health Aging 2012;16:184-187.

13. Janssen I, Heymsfield SB, Baumgartner RN, Ross R. Estimation of skeletal muscle mass by bioelectrical impedance analysis. J Appl Physiol 2000;89:465471.

14. Alexandre T da S, Duarte YA de O, Santos JLF, Wong R, Lebrão ML. Prevalence and associated factors of sarcopenia among elderly in Brazil findings from the SABE study. J Nutr Health Aging 2014;18:284-290. doi:10.1007/s12603-013-0413-0.

15. Cesari M, Fielding RA, Pahor M, Goodpaster B, Hellerstein M, Van Kan GA, Anker SD, Rutkove S, Vrijbloed JW, Isaac M, Rolland Y, M'Rini C, AubertinLeheudre M, Cedarbaum JM, Zamboni M, Sieber CC, Laurent D, Evans WJ, Roubenoff R, Morley JE, Vellas B. Biomarkers of sarcopenia in clinical trialsrecommendations from the International Working Group on Sarcopenia. J Cachexia Sarcopenia Muscle 2012;3:181-190. doi:10.1007/s13539-012-0078-2.

16. Kalinkovich A, Livshits G. Sarcopenia - The search for emerging biomarkers. Ageing Res Rev 2015;22:58-71. doi:10.1016/j.arr.2015.05.001.

17. Calvani R, Marini F, Cesari M, Tosato M, Anker SD, von Haehling S, Miller RR, Bernabei R, Landi F, Marzetti E, the SPRINTT consortium. Biomarkers for physical frailty and sarcopenia: state of the science and future developments: Biomarkers for physical frailty and sarcopenia. J Cachexia Sarcopenia Muscle 2015;6:278-286. doi:10.1002/jcsm.12051.

18. Scharf G, Heineke J. Finding good biomarkers for sarcopenia. J Cachexia Sarcopenia Muscle 2012;3:145-148. doi:10.1007/s13539-012-0081-7.

19. Batsis JA, Barre LK, Mackenzie TA, Pratt SI, Lopez-Jimenez F, Bartels SJ. Variation in the Prevalence of Sarcopenia and Sarcopenic Obesity in Older Adults Associated with Different Research Definitions: Dual-Energy X-Ray Absorptiometry Data from the National Health and Nutrition Examination Survey 1999-2004. J Am Geriatr Soc 2013;61:974-980. doi:10.1111/jgs.12260.

20. Lim S, Kim JH, Yoon JW, Kang SM, Choi SH, Park YJ, Kim KW, Lim JY, Park KS, Jang HC. Sarcopenic Obesity: Prevalence and Association With Metabolic Syndrome in the Korean Longitudinal Study on Health and Aging (KLoSHA). Diabetes Care 2010;33:1652-1654. doi:10.2337 / dc10-0107.

21. Batsis JA, Mackenzie TA, Barre LK, Lopez-Jimenez F, Bartels SJ. Sarcopenia sarcopenic obesity and mortality in older adults: results from the National Health and Nutrition Examination Survey III. Eur J Clin Nutr 2014;68:10011007. doi:10.1038/ejcn.2014.117.

22. Fried LP, Tangen CM, Walston J, Newman AB, Hirsch C, Gottdiener J, Seeman T, Tracy R, Kop WJ, Burke G, others. Frailty in older adults evidence for a phenotype. J Gerontol A Biol Sci Med Sci 2001;56:M146-M157.

23. Baumgartner RN, Koehler KM, Gallagher D, Romero L, Heymsfield SB, Ross RR, Garry PJ, Lindeman RD. Epidemiology of sarcopenia among the elderly in New Mexico. Am J Epidemiol 1998;147:755-763.

24. Chien M-Y, Huang T-Y, Wu Y-T. Prevalence of Sarcopenia Estimated Using a Bioelectrical Impedance Analysis Prediction Equation in CommunityDwelling Elderly People in Taiwan: PREVALENCE OF SARCOPENIA IN TAIWAN. J Am Geriatr Soc 2008;56:1710-1715. doi:10.1111/j.15325415.2008.01854.x.

25. Tichet J, Vol S, Goxe D, Salle A, Berrut G, Ritz P. Prevalence of sarcopenia in the French senior population. J Nutr Health Aging 2008;12:202-206.

26. Cuesta F, Formiga F, Lopez-soto A, Masanes F, Ruiz D, Artaza I, Salvà A Serra-Rexach JA, Rojano I Luque X, Cruz-Jentoft AJ. Prevalence of sarcopenia in patients attending outpatient geriatric clinics: the ELLI study. Age Ageing 2015;44:807-809. doi:10.1093/ageing/afv088.

27. Kalyani RR, Corriere M, Ferrucci L. Age-related and disease-related muscle loss: the effect of diabetes, obesity, and other diseases. Lancet Diabetes Endocrinol 2014:2:819-829. doi:10.1016/S2213-8587(14)70034-8.

28. Instituto Nacional de Salud Pública, 2013. Encuesta Nacional de Salud y Nutrición 2012. Resultados por entidad federativa. Inst Nac Public Healt Mx. Publishing Physics Web. https://www.insp.mx/produccion-editorial/ novedades-editoriales /3057-ensanut2012-resultados-entidad-federativa.html. Accessed 26 June 2016

29. Consejo Nacional de Población C, 2010. México en Cifras. Proyecciones de la Población 2010-2050. Publishing Physics Web. http://www.conapo.gob.mx/ es / CONAPO/Proyecciones. Accessed 4 June 2016. 